\title{
An appropriate multiple criteria decision making method for solving electricity planning problems, addressing sustainability issue
}

\author{
${ }^{1}$ N. Bagheri Moghaddam; ${ }^{2} *$ M. Nasiri; ${ }^{3}$ S. M. Mousavi \\ ${ }^{1}$ Department of Management and Accounting , Allameh Tabataba'I University, Tehran, Iran \\ ${ }^{2}$ Department of Industrial Engineering, AmirKabir University of Technology, Tehran, Iran \\ ${ }^{3}$ Department of Economic and Management, Sharif University of Technology, Tehran, Iran \\ Received 12 November 2010; $\quad$ revised 5 January 2011; accepted 17 April 2011; $\quad$ available online 1 June 2011
}

\begin{abstract}
In the past, decision making within the energy sector, especially in Iran, was limited to economic analysis. Lately, multiple criteria decision making has gained great popularity. However, this is not enough to make a right decision by considering sustainability. This paper deals with designing an appropriate multiple criteria decision making method to address the multifaceted nature of such problems. This task is the second precondition to make a decision which meets the sustainability criterion. This is done by revealing new facts about quantitative and qualitative data and the degree of compensation between the criteria. Moreover, this paper illustrates the capability of different methods with regard to sustainable energy planning and management in two steps: 1) comparison of two main approaches in the strategic energy planning context; 2) evaluation of multi attribute decision making methods and combining them. Combining four methods including Analytical hierarchy process, Preference ranking organization method for enrichment evaluation II, geometric mean and weighted sum seems to result in designing an appropriate method which meets the sustainability criterion. These contributions are proposed for comparing the renewable energy technologies with nonrenewable ones. Nevertheless, these seem to be applicable in any comparison between discrete alternatives in the energy sector.
\end{abstract}

Keywords: Analytical hierarchy process; Compensation; Decision analysis; Preference ranking organization method for enrichment evaluation II; Qualitative and quantitative data

\section{INTRODUCTION}

Nowadays, the important role of energy in improving welfare is undeniable as a strategic asset. This topic is a multifaceted and very complex matter. Existence of numerous structural (systems components) and procedural (systems functions) factors and their relations and dynamism cause such a complexity. From a structural point of view, an energy system is a combination of different subsystems with numerous actors within them. As an example, renewable energies are just a subsystem of the energy system, in which diverse actors, in public, university and business sectors, could be identified (Karapidakis et al., 2010). One can understand this complexity from a process oriented point of view. As an example, Research and Development, resource mobilization and market formation are just some illustrations of essential processes in these systems. Moreover, these

\*Corresponding Author Email:m.nasiri@aut.ac.ir Tel./ Fax: +989381011564 processes have many sub-processes. On one hand, analysis of energy systems is impossible without restraining their complexity. On the other hand, making a right decision about a system is impossible without analyzing that system. Thus, using a rational procedure in taking a right picture of reality, then restraining complexity and as a consequence, making the right decision about the modeled system is necessary.

Analyzing every system depends on the purpose of analysis. Therefore, one can use different methods to solve a problem, based on its nature. There are various problems with varying dimensions in the energy context. Some examples of these problems are capacity expansion planning, transmission and distribution network planning, load management and comparison of electricity generation technologies. These problems, as a part of all problems in the energy context, have different facets and varying degrees of importance. 
In fact, deciding about each of them has a different level of impact on the energy system; some of them having a short time span and others having longer. Thus, one can classify energy related problems with respect to their effective time span. Hobbs (1995) introduces such a classification, in which energy related problems are classified into short-term, mid-term and long-term problems. Long-term problems usually last more than ten years. Thus, decision making for such problems is a part of strategic planning (Tuzkaya, 2009; Tuzkaya et al., 2009). Mid-term problems are related to issues which are defined along several years or months like operational planning or designing power system plans with respect to existing facilities. When the time horizon is limited to several weeks or minutes, shortterm planning is relevant. Such problems are related to minimization of operational costs. The longer the time span of a problem , the more complex it is and the larger is its scope.

The problem discussed in this paper is considered within the context of energy, specifically the context of electricity planning. This problem is related to deciding whether or not to make a significant investment in electricity generation from wind energy resources by the Iranian government. This is a sustainable alternative to develop the energy system. There are two approaches to answer this question:

- To compare the condition in which the government invests in the wind sector with the condition in which the government does not make such an investment;

- To compare electricity generation from wind energy resources with electricity generation from other competing resources.

The second approach seems to be more appropriate for answering the question, because even if the investment was feasible, there might be more profitable options to invest in. In other words, investment in the wind sector may divest Iran of some advantages. Therefore, the primal question could be refined and be rewritten as: what is the position of electricity generation from wind in comparison to other resources? Based on this refinement, the existing problem falls into an appraisal class with respect to specific purpose of energy problems (Table 2).

Actually, Iran, like any other country, faces the resource limitation problem. Moreover, this problem is very important, as Iran is a developing country. Also, it is obvious that decision making about government investment in a subsystem of the energy sector has long-term effects on its energy system. Thus, this decision making problem falls into the category of longterm problems which increases the importance of the problem. This means that a right or wrong decision may lead to many advantages or disadvantages for Iran. This reasoning is justification of using a rational, clear and understandable decision making procedure.

To compare wind energy with other alternatives, it is necessary to see the problem from different points of view. In other words, considering different aspects is necessary for right decision making, which leads to sustainable development. The United Nations' World Commission on Environment and Development (WCED) defined sustainable development as: "development that meets the needs of the present without compromising the ability of future generations to meet their own needs” (WEC, 1986; WCED, 1987). This concept is a multifaceted one, including environmental aspects in addition to economical, social and cultural ones. With sustainability in mind, making a decision necessitates including different criteria in decision making process. Thus, using a multiple criteria evaluation of alternatives can offer significant contribution towards sustainable development of energy sector (Georgopoulou et al., 1997; Afgan et al., 2000; Zhou et al., 2006). Moreover, such techniques are gaining popularity in sustainable energy management (Huang et al., 1995; Pohekar and Ramachandran, 2004). There are two preconditions to make a decision which meets sustainability criterion:

- To define a set of sustainability indicators (Afgan and Carvalho, 2002);

- To design an appropriate approach which results in choosing a sustainable alternative (Polatidis et al., 2006)

There are numerous studies dealing with indicator definition, proposing guidelines and algorithms to choose a decision making method. However, few studies put effort into designing a method with sustainability considerations. Designing such a method is an important task, as the importance of environmental problems has risen owing to the green revolution (Chien and Shih 2007; Huang and Shih, 2009; Tehrani et al., 2009; 2010). It is the aim of this paper to design a method for Multiple criteria decision making (MCDM) with sustainability consideration. This is done based on illustrating some facts about the nature of qualitative 
and quantitative data. This paper is the result of a research conducted in 2010 to provide a methodology for deciding on investment in the wind sector by the Iranian government.

This problem can be identified as a part of the Strategic energy planning and management (SEPM) procedure (section 2). To design an appropriate method, a twoleveled approach is introduced. At the first level, different approaches that may meet the problem are identified and compared with each other. In this paper, two approaches are identified: Energy planning (EP) and its models and Multiple attribute decision making (MADM). These two bodies of literature play an important role in solving energy related problems. After comparing these two approaches and choosing the more appropriate one, an appropriate method of the selected approach is designed to solve the problem. Finally, some concluding remarks are presented.

\section{MATERIALS AND METHODS}

Strategic energy planning and management

UN (2002) defines SEPM as “an approach by which Governments (and stakeholders) take a long-term view of trends in natural resource use and environmental and social quality (described as the 'vision'), identify the changes necessary to bring these trends within sustainable limits and to establish a management framework to encourage key groups in society to achieve these goals”. Thus, this approach consists of vision stablishment with respect to sustainable development, designing strategies to meet the objectives and formulation of operational plans.

This approach is useful for determination of government strategies at macro levels in the energy sector and translating these strategies to operational plans. Thus, the Iranian government's decision about considering a significant share of energy supply for wind energy will have an extensive effect on its strategies in the energy sector.

This approach is a process which consists of different steps (Fig. 1). The UN (2002) gives some guidelines in 8 topics related to these steps (Table 1). Decision making about investment in the wind sector by the Iranian government is a strategy of the energy sector. Therefore, this problem can be defined in the fifth step in the following table. To solve this problem, it is common to employ two approaches, including EP and MADM. To find the more appropriate approach it is necessary to compare these approaches. Thus, in the third and forth sections of this paper, these two approaches are briefly introduced. Based on presented discussions, section 5 deals with comparing these approaches as a tool for formulating a strategy (step 5 in Table 1).

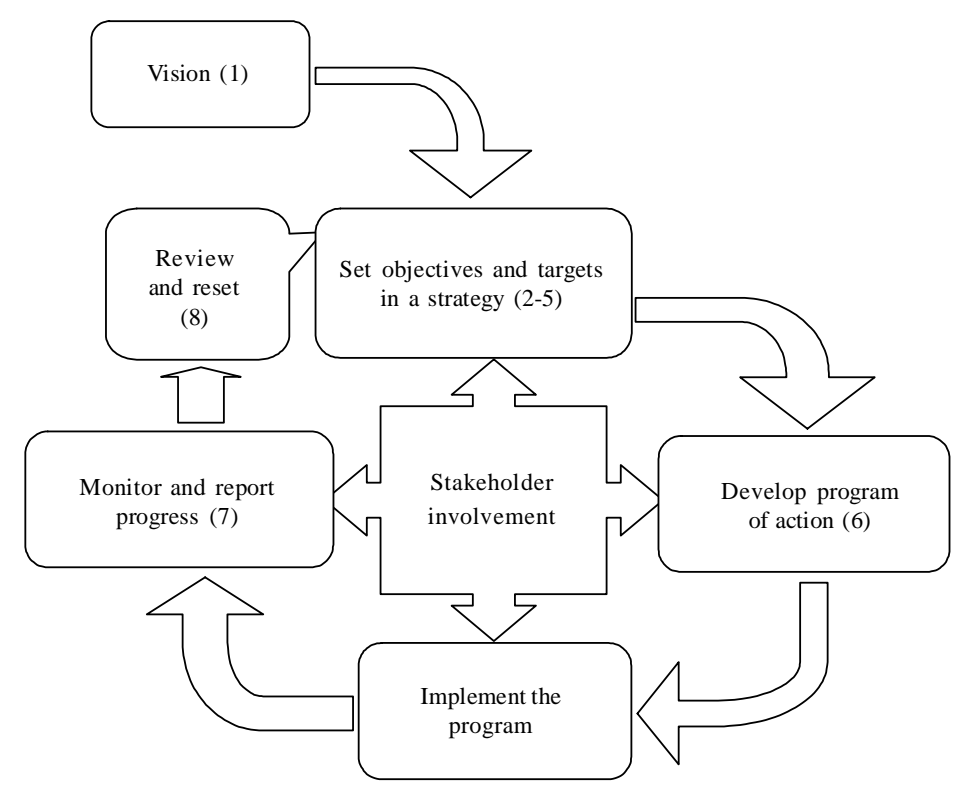

Fig. 1. Strategic energy planning and management approach (UN, 2002) 
Decision making for sustainable electricity planning

Table 1: Guidelines for using strategic energy planning and management approach (UN, 2002)

\begin{tabular}{|c|c|c|c|}
\hline Code & Name & Remarks & $\begin{array}{l}\text { Related step in SEPM } \\
\text { approach }\end{array}$ \\
\hline 1 & Vision & $\begin{array}{l}\text { Define an optimistic, realistic and long-term goal which is not } \\
\text { limited to the energy sector. }\end{array}$ & Vision \\
\hline 2 & Driving forces & $\begin{array}{l}\text { Identify macro trends affecting the energy sector, which may } \\
\text { or may not be controllable. }\end{array}$ & $\begin{array}{l}\text { Set objectives and targets in a } \\
\text { strategy }\end{array}$ \\
\hline 3 & $\begin{array}{l}\text { Identifying the } \\
\text { baseline }\end{array}$ & $\begin{array}{l}\text { Identify system's situation at the beginning of the planning } \\
\text { process. }\end{array}$ & $\begin{array}{l}\text { Set objectives and targets in a } \\
\text { strategy }\end{array}$ \\
\hline 4 & Developing scenarios & Identify different probable conditions during development. & $\begin{array}{l}\text { Set objectives and targets in a } \\
\text { strategy }\end{array}$ \\
\hline 5 & Formulating a strategy & $\begin{array}{l}\text { Translate vision into goals, objectives and strategies of the } \\
\text { energy system. }\end{array}$ & $\begin{array}{l}\text { Set objectives and targets in a } \\
\text { strategy }\end{array}$ \\
\hline 6 & $\begin{array}{l}\text { Formulating an action } \\
\text { plan }\end{array}$ & Translate objectives and strategies into targets and activities. & Develop program of action \\
\hline 7 & $\begin{array}{l}\text { Monitoring progress } \\
\text { and evaluation }\end{array}$ & $\begin{array}{l}\text { Develop a monitoring system to develop confidence about } \\
\text { meeting goals at the right time, using different methods like } \\
\text { defining a set of indicators. }\end{array}$ & Monitor and report progress \\
\hline 8 & $\begin{array}{l}\text { Adjusting to new } \\
\text { information }\end{array}$ & $\begin{array}{l}\text { Identify changes in the system due to implemented plans and } \\
\text { other factors to repeat the process. }\end{array}$ & Review and reset \\
\hline
\end{tabular}

\section{Energy planning}

$\mathrm{EP}$ at the energy sector level can be defined as a set of activities which find "a set of sources and conversion devices so as to meet the energy requirements / demands of all the tasks in an optimal manner" (Hiremath et al., 2007). Thus EP is about coordinated planning of different stages of the energy supply chain. Thery and Zarate (2009) split the supply chain into three parts based on states of energy:

- Primary energy which has not yet entered the conversion process,

- Distributed energy or energy carrier which is the result of the energy conversion process, but is not yet in the desired form to be used by the consumer, and

- Delivered energy which can be used directly by the consumer.

Due to complexity of energy systems, using computers to analyze these systems is inevitable. Using computer's computational power, it is possible to include a large amount of data and information in the analysis. Therefore many EP models have been developed in recent years. The quantity and quality (degree of adjustment to the reality) of these models have increased as computers' by computational power increase. Although there are various forms of EP models, one can figure out their general structure. For a better understanding of EP models, one can classify them from different points of view. Different classifications have been proposed by various authors.
Among others, Pandey (2002); Schrattenholzer (2005); Jebaraj and Iniyan (2006); Hiremath et al. (2007); van Beeck (1999) have proposed different classifications of such models. van Beeck (1999) reviewed different classifications and described attributes of famous EP models according to these classifications. Table 2 summarizes a part of classifications proposed in the literature.

With respect to Table 2, in the refined question:

- Alternatives appraisal is the aim of the problem,

- with low degree of endogenization, low extent of the description of non-energy sector components and low extent of the description of energy end-uses; but high extent of the description of energy supply technologies,

- top-down analytical approach,

- multi-criteria methodology,

- at the national level and in the energy sector,

- for a long time span and

- using quantitative as well as qualitative data at an aggregated level.

\section{Multiple atribute decision making}

Decision making is choosing among alternatives. Varieties of methods have been developed to analyze decision making so far. A subset of these, named multiple criteria methods, is about incorporating different aspects of alternatives into the decision making problem. These methods, among other 
Int. J. Environ. Sci. Tech., 8 (3), 605-620, Summer 2011

Table 2: Energy models classification from different points of view (van Beeck, 1999)

\begin{tabular}{|c|c|c|c|c|}
\hline Criterion & Sub criteria & Classes & Explanation & References \\
\hline \multirow{7}{*}{ Purposes } & \multirow{3}{*}{ General purposes } & Forecasting & "To predict the future" & Hourcade et al. (1996) \\
\hline & & Scenario analysis & “To explore the future" & van Beeck (1999) \\
\hline & & Backcasting & $\begin{array}{l}\text { "To look back from the future to the } \\
\text { present" }\end{array}$ & \multirow{5}{*}{ van Beeck (1999) } \\
\hline & \multirow{4}{*}{ Specific purposes } & $\begin{array}{l}\text { Energy demand } \\
\text { analysis }\end{array}$ & $\begin{array}{l}\text { "Focusing on demand as a function of } \\
\text { changes in population, income, and energy } \\
\text { prices" }\end{array}$ & \\
\hline & & $\begin{array}{l}\text { Energy supply } \\
\text { analysis }\end{array}$ & $\begin{array}{l}\text { "Focusing on technical (and perhaps } \\
\text { financial) aspects of energy supply" }\end{array}$ & \\
\hline & & Impact analysis & $\begin{array}{l}\text { "Analyzing impacts of using certain energy } \\
\text { systems or enacting certain policy } \\
\text { measures” }\end{array}$ & \\
\hline & & Appraisal & Comparing several options & \\
\hline \multirow{4}{*}{ Structure } & Degree of endogenization & $\begin{array}{l}\text { A range from low to } \\
\text { high }\end{array}$ & $\begin{array}{l}\text { Incorporating parameters within the model } \\
\text { equations as much as possible }\end{array}$ & \multirow[t]{4}{*}{$\begin{array}{l}\text { Hourcade et al. (1996) } \\
\text { van Beeck (1999) }\end{array}$} \\
\hline & $\begin{array}{l}\text { Extent of the description } \\
\text { of non-energy sector } \\
\text { components }\end{array}$ & $\begin{array}{l}\text { A range from low to } \\
\text { high }\end{array}$ & $\begin{array}{l}\text { "Including investment, trade, consumption } \\
\text { of non-energy goods and services, income } \\
\text { distribution, and so on." }\end{array}$ & \\
\hline & \multirow{2}{*}{$\begin{array}{l}\text { Extent of the description } \\
\text { of energy end-uses } \\
\text { extent of the description } \\
\text { of energy supply } \\
\text { technologies }\end{array}$} & $\begin{array}{l}\text { A range from low to } \\
\text { high }\end{array}$ & & \\
\hline & & $\begin{array}{l}\text { A range from low to } \\
\text { high }\end{array}$ & & \\
\hline \multirow{2}{*}{\multicolumn{2}{|c|}{ Analytical approach }} & Top-down & $\begin{array}{l}\text { Can only be used "if historical } \\
\text { development patterns and relationships } \\
\text { among key underlying variables hold } \\
\text { constant for the projection period" }\end{array}$ & \multirow[t]{2}{*}{$\begin{array}{l}\text { Grubb et al. (1993) } \\
\text { Hourcade et al. (1996) } \\
\text { van Beeck (1999) }\end{array}$} \\
\hline & & Bottom-up & $\begin{array}{l}\text { Are suited only "if there are no important } \\
\text { feedbacks between the structural evolution } \\
\text { of a particular sector in a strategy and the } \\
\text { overall development pattern" }\end{array}$ & \\
\hline \multirow{6}{*}{\multicolumn{2}{|c|}{ Underlying methodology }} & Econometric & $\begin{array}{l}\text { "Applying statistical methods to extrapolate } \\
\text { past market behavior into the future" }\end{array}$ & \multirow{3}{*}{$\begin{array}{l}\text { Berrie et al. (1985); Grubb } \\
\text { et al. (1993); Hourcade et } \\
\text { al. (1996); Kleinpeter } \\
\text { (1995) } \\
\text { World Energy Conference } \\
\text { (1986) } \\
\text { van Beeck (1999) }\end{array}$} \\
\hline & & Macro-Economic & $\begin{array}{l}\text { "Focusing on the entire economy of a } \\
\text { society and on the interaction between the } \\
\text { sectors" }\end{array}$ & \\
\hline & & Economic equilibrium & $\begin{array}{l}\text { "Focusing on the energy sector and its, } \\
\text { relations with the rest of the economy" }\end{array}$ & \\
\hline & & Optimization & $\begin{array}{l}\text { "Optimizing decisions for energy } \\
\text { investment in the energy sector" }\end{array}$ & \\
\hline & & Simulation & $\begin{array}{l}\text { "Reproducing a simplified operation of the } \\
\text { system" }\end{array}$ & \\
\hline & & Multi-criteria & $\begin{array}{l}\text { "Including other criteria than just economic } \\
\text { criteria" }\end{array}$ & \\
\hline \multirow{3}{*}{\multicolumn{2}{|c|}{ Mathematical approach }} & Linear programming & $\begin{array}{l}\text { With linear equations and continuous } \\
\text { variables }\end{array}$ & \multirow{3}{*}{$\begin{array}{l}\text { Kleinpeter (1995) } \\
\text { van Beeck (1999) }\end{array}$} \\
\hline & & $\begin{array}{l}\text { Mixed integer } \\
\text { programming }\end{array}$ & $\begin{array}{l}\text { With linear equations and continuous or } \\
\text { integer variables }\end{array}$ & \\
\hline & & $\begin{array}{l}\text { Dynamic } \\
\text { programming }\end{array}$ & $\begin{array}{l}\text { Optimizing through splitting the problem } \\
\text { into different stages }\end{array}$ & \\
\hline \multirow{2}{*}{\multicolumn{2}{|c|}{$\begin{array}{l}\text { Geographical coverage } \\
\text { Sectoral coverage }\end{array}$}} & \multirow{2}{*}{\multicolumn{2}{|c|}{$\begin{array}{l}\text { Global, regional, national, local, or project } \\
\text { uni-sectoral or multi-sectoral }\end{array}$}} & \multirow{4}{*}{$\begin{array}{l}\text { van Beeck (1999) } \\
\text { van Beeck (1999) } \\
\text { Grubb et al. (1993) } \\
\text { Thery and Zarate (2009) } \\
\text { van Beeck (1999) } \\
\text { van Beeck (1999) }\end{array}$} \\
\hline & & & & \\
\hline \multicolumn{2}{|l|}{ Time Horizon } & \multicolumn{2}{|c|}{ Short, medium, and long-term } & \\
\hline $\begin{array}{l}\text { Data } \\
\text { Requirements }\end{array}$ & $\begin{array}{l}\text { Dependence on experts } \\
\text { Level of aggregation }\end{array}$ & $\begin{array}{l}\text { Quantitative (independ } \\
\text { aggregated or detailed }\end{array}$ & ent) or qualitative (dependent) & \\
\hline
\end{tabular}


decision supporting systems and single objective decision making, form the decision analysis methods (Zhou et al., 2006). MCDM methods can be grouped into two sets, based on their possible solutions:

- Discrete solutions: MADM

- Continuous solutions: Multi Objective Decision Making (MODM)

Generally, MADM methods are about comparing several discrete alternatives with respect to independent criteria. Therefore, assessment of alternatives with respect to each criterion and relative importance of criteria (or some information about it) are main inputs of these methods, while the output is evaluation of alternatives based on the criteria. MADM methods have the power of indentifying the structure of complex decision making problems and elucidating decision makers' preferences. These methods are also understandable and reliable for the decision makers. Having these features, MADM methods are being used more and more by analysts.

Haralambopoulos and Polatidis (2003); Linkov et al. (2004); Pohekar and Ramachandran (2004) and Wang et al. (2009) among others, introduced the MADM process. Summing up these studies, one can propose an MADM process. Table 3 contains some explanations about the MADM process.

\section{Comparing approaches}

In this section, similarities and differences between EP and MADM are discussed from three aspects which influence the proper approach selection. These aspects can be named as:

- Goals: Represent the purpose of using an approach. Based on the goal of the problem, one or more approaches can be used.

- Methodology: Describes underlying methodology of each approach.

- Extent: Includes level of analysis in each approach, and aspects that can be incorporated into the analysis by approach (inclusiveness).

A more detailed description of each aspect and comparing approaches with respect to them, is the subject of the remainder of this section.

\section{Comparing approaches with respect to goals}

The goal represents the purpose of using an approach. On one hand, a goal is sought to be reached by solving any problem. On the other hand, each approach is used to reach a goal. Thus, an approach whose goal is compatible with the problem's goal must be used. Some EP models seek to find optimum shares in energy supply in different regions based on the demand for a long time. Consequently, these models

Table 3: Steps in MADM

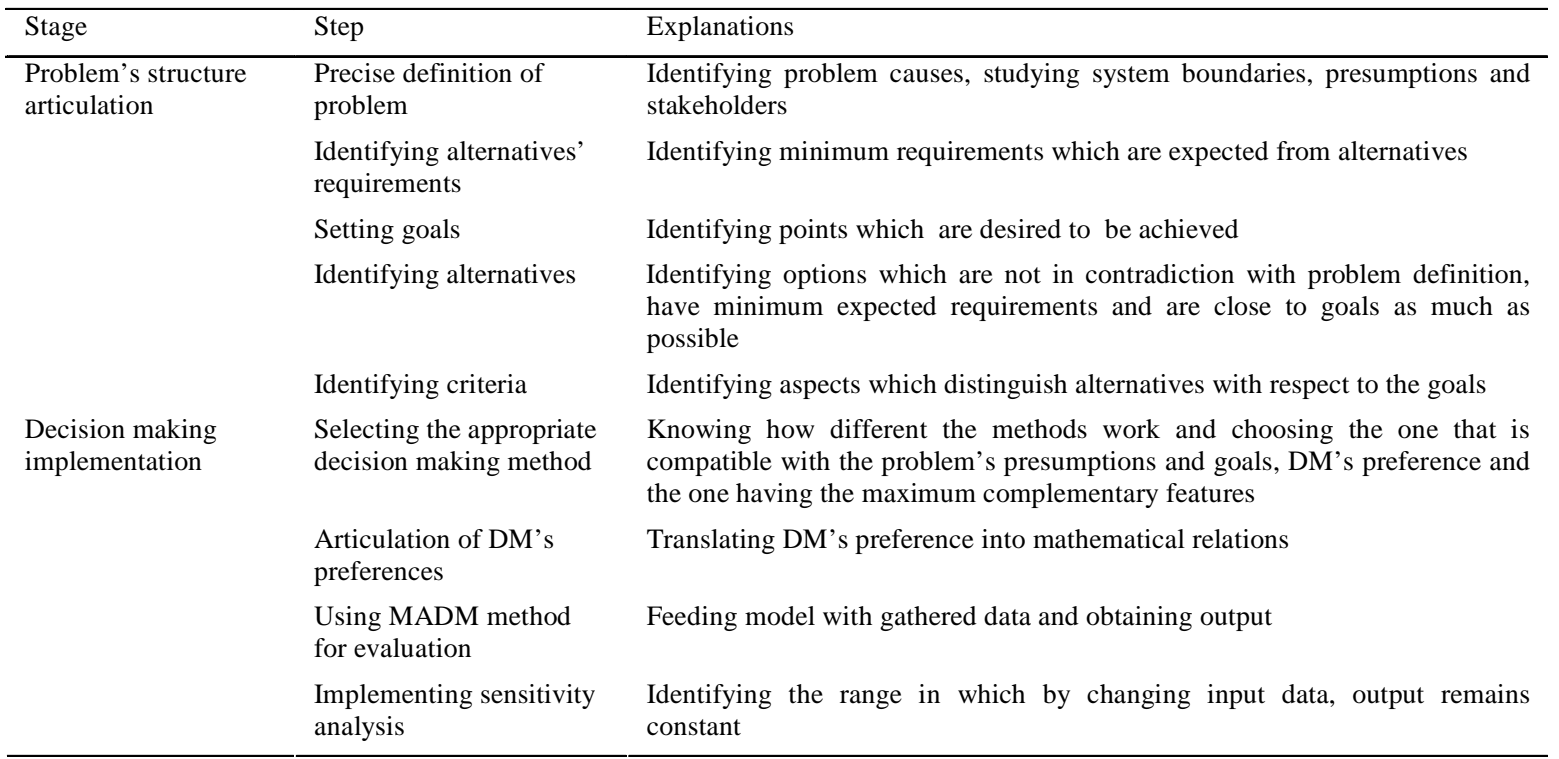


determine the optimum share of each energy resource in energy supply, using quantitative criteria. Therefore, these models do planning based on some presumptions (such as previous decisions and policy measures).

MADM methods are used to compare different alternatives, using quantitative and qualitative criteria. Usually, an ordered set of alternatives is the output of such models. Using this approach, one can choose, rank, describe or sort a set of alternatives, considering different aspects. MADM involves general methods which can be used in different applications including the energy sector. Roy $(1975,1996,2005)$ names four problematic issues for these methods: 1) Description, 2) Choice, 3) Sorting and 4) Ranking.

The aim of the present task is to study wind power justification by comparing it with other available power supply options. Therefore, the issue demands determining the position of wind power in relation with other independent options. Several points must be considered in this comparison. Some of these include economic, environmental and social security considerations. Focusing on these comparisons means to compare options in line with sustainable development in Iran. As it is clear in the task aim, the purpose of this study is not to determine the optimum flow of energy supply in different regions or to determine shares of different supply options. Rather, the qualitative and quantitative data are used together to solve this problem. Seemingly, MADM's goals match with the problem's goals. In addition, the EP approach (depending on the method used) can be used to answer questions other than questions related to the problem.

Comparing approaches with respect to methodology

The methodology used in each approach includes techniques that are used in it. Moreover, any technique uses a particular type of data. For example, some techniques use quantitative data; some other use qualitative data and some of them use a combination of them.

EP uses multi-objective decision making methods, such as linear and nonlinear programming to achieve its goals. These methods interact with continuous spaces. Most studies conducted in this context are based on complicated mathematical models and powerful decision support system software (Ferreira, 2007). As a result of extensive use of mathematical formalism, too much simplifying assumptions are incorporated in such methods.
The MADM approach does not describe objectives and constraints in the form of mathematical functions. It identifies characteristics of a limited set of alternatives to evaluate them and compare them with each other. The main power of these models is their ability in structuring issues that have been defined with ambiguity (Dialoulaki et al., 2005). In this way, these methods provide a deep insight into alternatives. Part of planning in the energy context can be done based on the MADM approach to compare alternatives in this context, such as scenarios, strategies, technologies and so on (Ferreira, 2007). Then, proposed options are characterized by a set of criteria in different ways to aggregate all data. This approach often needs the participation of stakeholders and desicion makers (DMs) in the weight assignment process, DM's preference elucidation and tradeoffs. Models used in this approach are able to offer options' characteristics to DMs. These points lead to a more transparent desicion making process than when complex mathematical functions are used.

In the raised issue, it is not desired to use sophisticated mathematical techniques to solve the problem. Moreover, the most important advantage in using an approach is that it helps to structure the issue in order to understand the features of the alternatives. Besides, it is not reasonable to compare different options, using just quantitative data.

In conclusion, methodologies used in the energy planning approach deal with continuous spaces; while in the present matter, the answer space is discrete. Moreover, this approach typically uses sophisticated mathematical models, in which the development and validation for a country consumes much time and cost. The MADM approach identifies issues related to alternatives and characterizes them. This way, DMs (and stakeholders) can systematically compare alternatives. Therefore, methods used in the MADM approach are in compliance with conditions of the problem.

\section{Comparing approaches with respect to extent}

The extent of approaches is comparable from two perspectives. These two perspectives are the level of analysis and inclusiveness of each approach. In order to understand the concept of level, a hierarchy can be imagined (Fig. 2). In a hierarchy, by moving towards higher levels, more macro issues will be raised. In addition, by moving towards higher levels, issues' 


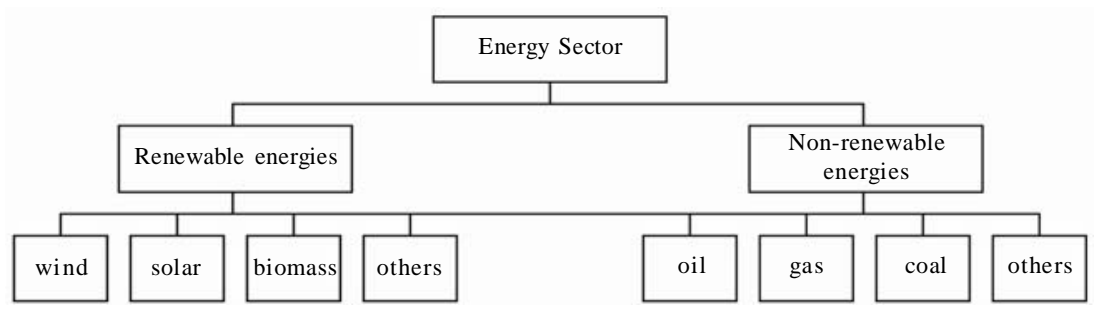

Fig. 2: A hierarchy in the energy sector

details will be reduced. Otherwise, the complexity of the subject will be increased. Inclusiveness means different aspects of the subject are incorporated. For example, some approaches have the ability of involving political considerations. In this example, the political considerations are one aspect to analyze the subject (along with other considerations such as economic, environmental and social).

Energy planning (depending on the aim of the model used) deals with the country's energy sector as a whole (renewable and nonrenewable) and its various parts (supply, carrier and so on). First, some models, focusing on one sector (e.g. electricity only) were developed and then more complex models were created. Also, in order to achieve EP targets, some considerations, such as demand growth rate and differences between different regions of the country are noted. However, some considerations in the context of EP gain little attention by EP models or are even missed.

The MADM approach performs decision making based on type and purpose of the problem (both at macro level and at lower levels). Due to the ability of this approach in solving specific types of problems (multiple criteria decision making in discrete spaces), some considerations raised in this approach are different from considerations raised by other approaches and other considerations that are common. For example, electricity demand growth and diversity of various geographic areas in supply and demand are not considered in MADM, since this approach is suitable for comparison and is not used for determining shares.

The raised issue is a relatively macro problem in the energy sector and needs meso level data (neither detailed data nor aggregated data) to be included in evaluating alternatives. Moreover, it is desired to consider different aspects (as much as possible) in comparing alternatives. With respect to this aim, EP models are not compatible with the problem's requirements.

\section{Proper approach}

Based on comparing approaches from the three mentioned point of view, the MADM approach seems to be qualified for being used in the planning process. It is worth to mention that if the problem requires determining shares of energy supply alternatives, the EP approach would be more appropriate (again at the cost of missing some aspects). Therefore, MADM methods will continue to be studied in this paper.

\section{RESULTS AND DISCUSSION}

\section{Appropriate MADM method}

To design an appropriate MADM method, it is necessary to characterize the methods. Then, it will be possible to design an appropriate method with respect to the problem's conditions. Hence, in this section after characterizing most probable methods, the most suited one with problem conditions will be identified.

Generally, one can classify MADM methods into elementary and advanced. Elementary methods use a qualitative approach, while advanced methods use a quantitative approach in decision making. It must be noted that a qualitative approach means an approach with minimal mathematical operations, while a quantitative approach utilizes many more of such operations. Thereby, quantitative and qualitative terms are not relevant to input data. Table 4 includes a brief summary of each method.

On one hand, various MADM methods are being applied to the same data results in different outputs. On the other hand, each decision making method is suitable for some problem conditions. Therefore, based on the raised problem conditions, the most appropriate method must be chosen. As a consequence, a key question in every MADM problem is "what is the most 
Table 4: Popular MADM methods

\begin{tabular}{|c|c|c|c|}
\hline Type & Name & Summary & References \\
\hline \multirow{4}{*}{ Elementary } & Lexicography & $\begin{array}{l}\text { First of all, alternatives are ranked with respect to the most } \\
\text { important criterion. Then, alternatives in the same position are } \\
\text { ranked with respect to the second most important criterion and this } \\
\text { process goes on until alternatives are compared with respect to all } \\
\text { criteria. Countries in Olympic Games are ranked based on numbers } \\
\text { of gold, silver and bronze medals using this method. }\end{array}$ & \multirow[t]{2}{*}{ Fishburn $(1974,1975)$} \\
\hline & Pros and cons & $\begin{array}{l}\text { A list of pros and cons is provided for each alternative. Then, an } \\
\text { alternative which has more pros and less cons is chosen. }\end{array}$ & \\
\hline & $\begin{array}{l}\text { Maximin and } \\
\operatorname{maximax}\end{array}$ & $\begin{array}{l}\text { The Maximin method is based on avoidance of bad performance as } \\
\text { much as possible. Therefore, this method maximizes alternatives' } \\
\text { minimum performance. Thus, an alternative whose weakest } \\
\text { performance is better than other alternatives' weakest performance } \\
\text { is chosen. The Maximax method uses a similar strategy, except that } \\
\text { it maximizes the best performance. }\end{array}$ & Linkov et al. (2004) \\
\hline & $\begin{array}{l}\text { Conjunctive and } \\
\text { disjunctive }\end{array}$ & $\begin{array}{l}\text { First of all, a threshold value is determined for each criterion. Then, } \\
\text { the conjunctive method removes alternatives which do not pass the } \\
\text { threshold for all criteria. Also, the disjunctive method removes } \\
\text { alternatives which do not pass the threshold for at least one } \\
\text { criterion. }\end{array}$ & Linkov et al. (2004) \\
\hline \multirow{5}{*}{ Advanced } & (AHP) & $\begin{array}{l}\text { Decision making begins by designing an analytical hierarchy tree. } \\
\text { This hierarchy is a graphical representation of the real complex } \\
\text { problem. On the top level, the problem's objective is mentioned } \\
\text { while other levels are comprised of criteria and alternatives. Then in } \\
\text { a bottom-up approach, DM(s) do a pairwise comparison for each } \\
\text { factor in each level with respect to upper level factors. Different } \\
\text { methods are introduced in literature to compute the final value of } \\
\text { alternatives based on the Eigenvector. }\end{array}$ & Saaty $(2000,2005)$ \\
\hline & (MAUT) & $\begin{array}{l}\text { MAUT is a systematic method for identifying and analyzing several } \\
\text { variables to provide a common basis for decision making. A key } \\
\text { step in this method is characterizing a multi attribute utility } \\
\text { function. To do this, identifying single attribute utility functions and } \\
\text { their weights is necessary. Formulating a multi attribute utility } \\
\text { function provides the possibility of computing each alternative's } \\
\text { final value. }\end{array}$ & Dyer (2005) \\
\hline & ELECTRE & $\begin{array}{l}\text { This set of methods is based on a pairwise comparison and } \\
\text { outranking relation. These methods, based on the chosen version, } \\
\text { utilize preference, indifference and incomparable relations. An } \\
\text { outranking relation is based on two basic concepts: " } 1 \text { ) } \\
\text { Concordance: For an outranking aSb to be validated, a sufficient } \\
\text { majority of criteria should be in favor of this assertion. 2) Non- } \\
\text { discordance: When the concordance condition holds, none of the } \\
\text { criteria in the minority should oppose too strongly to the assertion } \\
\text { aSb." }\end{array}$ & $\begin{array}{l}\text { Figueira et al. (2005); } \\
\text { Roy }(1990,1991)\end{array}$ \\
\hline & PROMETHEE & $\begin{array}{l}\text { In this set of methods, DMs' preference structure is articulated } \\
\text { using a mathematical function based on the difference in values of } \\
\text { alternatives. Then, based on distance between each pair of } \\
\text { alternatives, their relative value is computed. The relative position } \\
\text { of each alternative is characterized applying another mathematical } \\
\text { function. }\end{array}$ & $\begin{array}{l}\text { Brans et al. (1984, } \\
\text { 1986); Brans and } \\
\text { Mareschal (2005) }\end{array}$ \\
\hline & Other methods & $\begin{array}{l}\text { This set of methods includes QUALIFLEX, ORESTE, REGIME, } \\
\text { ARGUS, EVAMIX, TACTIC and MELCHIOR methods. These } \\
\text { methods, which implement the outranking concept, prevent DMs } \\
\text { from quantification of qualitative values as much as possible. In } \\
\text { these methods, alternatives are ranked or chosen utilizing a } \\
\text { quantitative approach. }\end{array}$ & $\begin{array}{l}\text { De Keyser and Peeters } \\
\text { (1994); Martel and } \\
\text { Matarazzo (2005); } \\
\text { Paelinck (1976, 1977); } \\
\text { Voogd (1982) }\end{array}$ \\
\hline
\end{tabular}


appropriate method for solving the problem?” Many models and methods have been developed in literature to answer this question. These models and methods focus on compatibility of MADM methods' objectives and attributes with the problem's objective and attributes. Some authors just introduce several guidelines for choosing a method as a part of the MADM process, while others focus on this subject. Reviewing studies done by both groups of authors provides a basis for designing an appropriate method of decision making.

Løken (2007) introduces validity of method (what it is supposed to measure) as the most important criteria in choosing an MCDM method for energy planning problems. Providing DMs with all the information they need, compatibility with the accessible data (appropriateness) and ease of use and understanding are also evaluated as important criteria by this author.

Polatidis et al. (2006) introduce prerequisites of the MADM methods and their justification. These prerequisites are the following capabilities: weight elicitation, using critical threshold values or veto, integrated comparability, handling qualitative and quantitative information, rigidity, handling group decision-making, graphical representation, ease of use, performing sensitivity analysis, incorporating a variety of alternatives and criteria, implementing consensus seeking procedures, incorporation of intangible aspects, incommensurability, treatment of uncertainty, allowing partial compensation, providing hierarchy of scale, providing concrete meaning for parameters used, acknowledging learning dimension and considering temporal aspects. It seems that some of these criteria are related to model input, some others are related to analytical processes and the rest of them are relevant to model output for DMs. This diversity in criteria somehow represents considering almost all aspects by these authors.

Guitouni and Martel (1998) mention several guidelines for choosing an appropriate MADM method. Their remarks are related to the following issues:

- Incorporating stakeholders in the decision making process

- Compatibility of method with DMs way of thinking

- Compatibility of method with desired problematic

- Ability of handling available data

- Compatibility of method with DMs expectations with respect to degree of compensation
- Compatibility with the problem's assumptions

- Existence of decision support system software

Deason (1984) introduces a set of descriptors of problem situation. Based on these descriptors an algorithm for choosing the appropriate method is proposed. Gershon (1981) proposes 27 criteria in order to choose the appropriate method. These criteria are classified into 4 groups which are named Mandatory binary criteria, Non-mandatory binary criteria, Technique dependent criteria and Application dependent criteria. Using these criteria, MADM methods are compared based on a distance metric.

Tecle (1988) classifies 49 characteristics into four groups: describing the problem, describing the DM or analyst, describing the techniques, and describing the solution obtained. Tecle (1988) also reviews and classifies 70 MADM methods. Due to the difficulty in evaluating all methods with respect to all the characteristics, this author evaluates 16 methods with respect to 24 characteristics.

As mentioned in previous sections, after defining the problem, identifying alternatives and criteria and characterizing the problem's objectives and condition, one can design the appropriate method. The previous subsection provided a picture in which different aspects of designing an appropriate method were included. This subsection represents efforts to design a well-suited method with raised problem, using gained insights. To do so, important aspects by which available methods must be compared are proposed based on reviewing the literature. Then, a well-matched method is identified.

It seems that the most important criterion in designing a method is its compatibility with the problem's objective. This criterion is explicitly mentioned in a set of criteria proposed by Guitouni and Martel (1998) and Løken (2007), while implicitly mentioned by other authors. In this paper, this criterion is defined based on the problematic concept. The raised problem in this study is justification of electricity generation from wind energy resources by comparing it with other alternatives. Wind energy is justified as it gains a winning position among others. To determine the relative position of wind energy, its rank needs to be identified. Therefore, the objective of this problem is to rank alternatives. Thereby, the designed method must have ranking problematic. Another requirement in the present problem is handling both quantitative and qualitative data. Almost all of the available methods 
have the ability of accepting mixed data. This aspect is explicitly introduced by all reviewed studies. But there is a delicate point which is missed by authors. It is not sufficient to accept mixed data by a method to judge whether it is qualified or not. A relevant key question is "how does the method handle these data?" For more explanation, quality and quantity concepts must be described at first. A variable is called quantitative, if it can be measured by a reliable (without change) unit. So, different people have similar ideas about the amount of that variable (without considering error). Thus, quantitative variables are expert independent. An example is powerplant capacity. On the contrary, qualitative variables are expert dependent as it is impossible to define a reliable unit for them. Therefore, various people have different ideas about those variables. In such cases, analysts have no way to include such variables except to rely on expert opinion. A relevant example can be degree of political tension as a result of using a technology. In decision making problems, analysts try to transform qualitative variables into quantitative ones, using indicators. In some cases it is not possible to do so and some variables remain qualitative. As quantitative variables are measured based on units of measurement, it is possible to compute the distance between two alternatives with respect to quantitative criteria. But, it is not possible to compute the distance with respect to qualitative criteria due to lack of unit. For example, suppose that the capacity of powerplant A is $2000 \mathrm{MW}$ and capacity of powerplant B is $1500 \mathrm{MW}$. Based on the unit of measurement one can say the capacity of powerplant A is $500 \mathrm{MW}$ more than powerplant B. Now, assume that using technology A results in high tension but using technology B results in low tension. No one can say how much more tension is the result of using technology A instead of technology B. This is because there is no unit for measuring tension. Threfore, dealing with qualitative criteria, one can just tell approximately relative values of the two alternatives. To understand the result of this difference, the following example seems to be helpful.

A reality about the value of two options with respect to an aspect can be expressed in two ways. The first expression is "value of the first option is 2 and value of the second option is 4". The second expression is "value of the second option is twice greater than that of the first one". The first expression contains more data. The first type of expressions can be stated for both quantitative and qualitative criteria, while it is impossible to use the second type for quantitative ones. Describing quality and quantity concepts helps to distinguish methods based on the way they deal with data. Relevance of this fact to designing an MADM method is the preference of DMs. As an explanation, it can be said that if DMs think based on the distance between two alternatives, a method which is based on distance must be used. This issue is relevant in a quantitative criteria set, as there is a unit defined for the quantitative one. But, as it is not possible to think based on distance with regard to qualitative criteria, methods based on relative judgment shall be used. This means that the decision must be made based on relative importance or utility of alternatives. In the mentioned example, one can say technology A results in high tensions, compared with technology B.

The next aspect is DMs' preference elucidation. This aspect is introduced by reviewed studies under different titles. At least three dimensions can be named for this aspect. The first one is the variety of relations defined for comparing alternatives. As an example, in some models just $I$ (indifference) and $P$ (preference) relations are used, while other methods utilize $\mathrm{R}$ (incomparable) relation as well. Figueira et al. (2005) provide a detailed description about these relations. The second dimension is about the evaluation method by DMs. For cases in which DMs prefer pairwise comparisons, using methods based on such comparisons are desired. The third one is related to degree of compensation allowed by the model. Utility methods are compensatory, while outranking methods are semi- or non- compensatory.

Another criterion which is not addressed by the authors is degree of using the method in the problem's context. In fact, the more a method is used in a context, the more it will be legitimized in that context from DM's point of view, because using a method which is used beforehand in the same context assures DMs that a right method is used. As a consequence, DMs rely on the method's results. As the second advantage of considering this criterion, continual use of a method in a context, provides experience about its application. This leads to fewer mistakes and more efficient implementation. For example, De Keyser and Peeters (1996) remark issues which must be noted for applying the PROMETHEE method.

Other criteria that must be noted in designing an appropriate approach are: ease of use and 
understanding, degree of dependence on DMs, ability of supporting group decision making, rigidity, using meaningful parameters and availability of decision support system software. These criteria are remarked by the authors.

The mentioned criteria provide a basis for removing methods which do not have minimum expected criteria from the list of methods. In the problem raised, identifying the order of alternatives is desired. As complete ranking of alternatives is needed, the position of each alternative must be determined. Therefore, using $R$ type relation is not relevant. This means, noncompensatory methods won't be used. All of identified methods except ORESTE and some versions of ELimination Et Choix Traduisant la REalité(ELECTRE) and PROMETHEE family of methods provide complete ranking (Guitouni and Martel, 1998).

Input includes the quantitative and qualitative data. Therefore, the designed method must handle both types of data. Among the mentioned methods, QUALIFLEX, REGIME, ORESTE and Achieving Respect for Grades by Using ordinal Scales (ARGUS) are not qualified. QUALIFLEX is well-suited when all criteria are qualitative. Due to normalization in the REGIME method, a large amount of data will be missed. ORESTE and ARGUS methods lead to similar results. From DM's point of view, a comparison between alternatives must be based on the distance between them with respect to quantitative criteria. For example, in comparing three alternatives with respect to their costs, it is assumed that alternatives A, B and C cost 2, 4 and 8 units respectively. From DM's point of view, relative utility of $A$ in relation to $B$ is more than that of $B$ in relation to $\mathrm{C}$. Thus, the relative value of alternatives is not linear with respect to the cost. As a consequence, methods which are not based on distance are not appropriate to be used in decision making with quantitative criteria.

As mentioned before, elucidation of DMs' preference is a 3-dimensional criterion. With respect to the first dimension, DMs do not use $R$ relation as they want to see the complete ranking of alternatives. Thus, all utility based methods and those ranking methods that do not include $R$ relation are qualified with respect to this dimension. According to the second dimension, QUALIFLEX, REGIME, ORESTE, ARGUS, EVAMIX, TACTIC, Méthode d'ELimination et de Choix Incluant les relation d'ORdre (MELCHIOR) and ELECTRE family must be removed. On one hand, these methods have complex mathematical computation and some of them need further knowledge such as graph theory, linear algebra and quadratic programming. On the other hand, DMs in such a managerial level neither have such knowledge, nor have the time to learn them. As a consequence, they won't know what is occurring in the decision making process. Since they see these methods as a black box, they won't rely on their results (Løken, 2007). Moreover, some methods are not flexible enough to model DMs' preference. This makes a difference between PROMETHEE and Multi attribute utility theory (MAUT) with other methods, as they provide unlimited functions. In these methods, DM can choose a function which fits with its preference structure. In relation with the third dimension, Polatidis et al. (2006) recommend using methods with a lower degree of compensation as a consideration of sustainability issues. This approach for considering sustainability issues is also acknowledged in this paper. Among the survivor methods, those which have more supplementary features are more desired. Among MADM methods, "elementary” methods are not qualified as they are designed for simple problems. Simple problems are those in which few alternatives and criteria are included. Also, due to reasons mentioned above, among advanced methods, the "other methods" group and ELECTRE family seem to be inappropriate. The three remaining methods in the list are Analytical hierarchy process (AHP), PROETHEE family and MAUT. An interesting matter is that these methods (as well as ELECTRE family) are the most frequently used in the energy sector (Dialoulaki et al., 2005; Kahraman et al., 2009; Pohekar and Ramachandran, 2004; Polatidis et al., 2006; Wang et al., 2009). Also, their problematic is ranking (Figueira et al., 2005; Guitouni and Martel, 1998). Among these methods, MAUT is very time consuming and is highly dependent on DM's preference. These two reasons can be causes of its relatively reduced usage in recent years. This reduction is reported by Zhou et al. (2006).

As mentioned above, computing alternative values with respect to qualitative criteria based on their paired ratio is desired. This means determining how many times the $i$ th alternative is more valuable than the $j$ th alternative. Also, with respect to quantitative criteria, decision making must be based on the distance between alternatives. This means how greater the ith alternative is as compared to the $j$ th alternative. As the AHP method is based on ratio and PEOMETHEE family 
is based on distance, they seem to be compatible with qualitative and quantitative criteria respectively. PROMETHEE family includes PROMETHEE I, II (Brans, 1982; ), III, IV, V (Brans and Mareschal, 1995), GDSS (Macharis et al., 1998), TRI and CLUSTER (Fiqueira et al., 2005). Among the PROMETHEE family, PROMETHEE II is more desired as it provides complete ranking and is user friendly (Tuzkaya et al., 2009; Behzadian et al., 2010). Another issue raised in relation with implementing procedures is weighting the criteria. There are different methods for weighting the criteria. Usually, the weighting methods are applied in cases where weighting the criteria is not provisioned by the designed MADM method. In other words, in such methods, weights of criteria are input data. Since the AHP method is based on relative importance, it can be used to set the criteria weights. Another advantage of using AHP, is handling of group decision making. In this way, group decision making is provisioned by the method and there is no need to use any other methods. So, in this study, AHP is proposed to be used for weighting the criteria, handling group decision making and comparison of alternatives with regard to qualitative criteria. The PROMETHEE II method is also used for comparison of alternatives with regard to quantitative criteria because of its flexibility in decision modeling and appropriate handling of quantitative data (least amount of loss of information). Finally, it can be said that the experts would not choose alternatives with better economic performance criteria at the cost of environmental issues, security, political, and other criteria. This means the use of semi-compensatory decision making methods is desired. In this study, economic criteria are also quantitative and others are qualitative. Thus, in the comparison of alternatives with respect to both types of criteria, an equation which selects alternatives with fair performance with respect to all aspects should be used. For this reason, aggregation of alternative values with regard to qualitative and quantitative criteria can be computed using the following equation.

$V_{a}=E_{a}^{w_{E}} \cdot N_{a}^{w_{N}}$

Where, $V_{a}$ is value of $a$. Also $E_{a}, N_{a}, W_{E}$ and $W_{N}$ represent the value of $a$ with respect to quantitative criteria, value of $a$ with respect to qualitative criteria, weight of quantitative criteria and weight of qualitative criteria, respectively. As this relationship is a geometric mean, those alternatives that perform fairly with respect
Table 5: Alternatives value computation, using geometric mean

\begin{tabular}{lccc}
\hline Criteria & $1^{\text {st }}$ criteria & $2^{\text {nd }}$ criteria & \multirow{2}{*}{ Value } \\
\cline { 1 - 3 } Criteria weight & 0.5 & 0.5 & \\
$1^{\text {st }}$ alternative & 0.1 & 0,9 & 0.3 \\
$2^{\text {nd }}$ alternative & 0.5 & 0.5 & 0.5 \\
\hline
\end{tabular}

to different criteria are more desired than ones that perform well with respect to some criteria and have bad performance with respect to some others. Table 5 can help to better understand this issue.

Therefore, an alternative with good performance with regard to all criteria is more desired than ones that perform well in several criteria and have bad performance with regard to others. If an arithmetic average were to be used to calculate values, the numbers obtained from both alternatives would be equal.

As an extension of this method, criteria can be classified into different categories so that existing criteria in each category can offset each other perfectly, but criteria in various categories cannot fully compensate each other (semi-compensatory). Three cases can be expected in relation to criteria for each category:

1) All criteria are qualitative: use AHP to compute the value of each alternative.

2) All criteria are quantitative: use PROMETHEE II to compute the value of each alternative.

3) Criteria are qualitative and quantitative: use PROMETHEE II to compute the value of each alternative with respect to quantitative criteria and AHP to compute values with respect to qualitative ones.

Then use the following equation to compute the final value of all criteria within the group:

$V_{a: C_{m}}=W_{E} \cdot E_{a: C_{m}}+W_{N} \cdot N_{a: C_{m}}$

Where $V_{a: C_{m}}$ is the value of $a$ for criteria group $C_{m}$ (criteria in the $m$ th group). Also, $W_{E: C_{m}}, E_{a: C_{m}}, W_{N: C_{m}}$ and $N_{a: C_{m}}$ represent the sum weights of quantitative criteria belonging to the $m$ th group, value of $a$ with respect to quantitative criteria belonging to the $m$ th group, sum of weights of qualitative criteria belonging to the $m$ th group and value of $a$ with respect to qualitative criteria belonging to the $m$ th group, respectively. 
Finally, the value of $a$ can be computed using the following equation:

$V_{a}=\prod_{i=1}^{L} V_{a: c_{i}}^{W c_{i}}$

Where $V_{a}$ represents the value of $a$ and $V_{a: C_{i}}$ and $W_{C_{i}}$ are the value of $a$ with respect to the ith group of criteria and weight of the ith group of criteria, respectively. It is assumed that all criteria are classified into L mutually exclusive groups. An implicit assumption in the above equation is that the compensation relation is a transitive one. This means, it is assumed that DM compares compensatory criteria in a reasonable manner. So, there will be no case where one criterion belongs to more than one group.

\section{CONCLUSION}

This paper dealt with designing an appropriate method for decision making regarding a given problem using a two-level approach. At the first level, two popular approaches were reviewed and were compared with each other from three perspectives. At the second level, different MADM methods were reviewed and compared.

During this review, some untapped aspects about quantitative and qualitative data and their relevance to the method designing task were revealed. It was clarified that quantitative data provides DMs with more information by doing analysis based on distance. Analyzing data based on ratio causes information gaps. Therefore, it is proposed that depending on which type of data is desired to be analyzed, different methods shall be used.

Based on a review of the literature and supplementary reasoning, the most important aspects in selection (one can say design, as the proposed method is made up of four MADM methods, named AHP, PROMETHEE II, geometric mean and weighted sum) of the appropriate method are introduced. Some of these aspects were new to the literature. Finally, the generalized method of decision making has been proposed using the four mentioned MADM methods by considering sustainability.

Since reasoning for design of the method was general enough, it seems to be applicable in similar cases (any comparison between discrete alternatives in any chain of energy sector) which meet the following conditions:
1) Sustainability issues are at the center of attention and DMs are serious to incorporate the sustainability aspect into decision making problems. This leads to designing methods with lower degrees of compensation.

2) The value of alternatives is not linear in relation with their quantities in quantitative criteria from DMs point of view.

3) DMs are not familiar with complex MADM methods and do not have enough time to learn how they work.

\section{ACKNOWLEDGMNETS}

This paper is a partial result of the \#. project 88/51, supported by the Renewable Energy Organization of Iran.

\section{REFERENCES}

Afgan, N. H.; Carvalho, M. G., (2002). Multi-criteria assessment of new and renewable energy power plants. Energy, 27 (8), 739-755 (17 pages).

Afgan, N. H.; Carvalho, M. G.; Hovanov, N. V., (2000). Energy system assessment with sustainability indicators. Energ. Policy, 28 (9), 603-612 (10 pages).

Behzadian, M.; Kazemzadeh, R. B.; Albadvi, A.; Aghdasi, M., (2010). PROMETHEE: A comprehensive literature review on methodologies and applications. Eur. J. Oper. Res., 200 (1), 198-215 (18 pages).

Berrie, T., (1985). Integrated Energy Planning: A Manual. Codoni, R. P.; Hichun; Ramani, K. V., (Eds.). Vol. 1: Energy Data, Energy Demand. Asian and Pacific Development Center.

Brans, J. P., (1982). Lingenierie de la decision. Elaboration dinstruments daide a la decision. Methode PROMETHEE. Nadeau, R.; Landry, M., (Eds.). Laide a la Decision: Nature, Instrument s et Perspectives Davenir. Presses de Universite Laval, Quebec.

Brans, J. P.; Mareschal, B., (1995). The PROMETHEE VI procedure. How to differentiate hard from soft multicriteria problems. J. Decision Sys., 4 (1), 213-223 (11 pages).

Brans, J. P.; Mareschal, B., (2005). PROMETHEE Methods. in: Figueira, J., Greco, S., Ehrgott, M. (Eds.), Multiple criteria decision analysis: state of the art surveys, Springer Science and Business Media, Inc., Boston.

Brans, J. P.; Mareschal, B.; Vincke, P., (1984). PROMETHEE: A new family of outranking methods in multicriteria analysis. Brans, J. P. (Ed.). Operational Research, Amsterdam, NorthHolland.

Brans, J. P.; Mareschal, B.; Vincke, P., (1986). How to select and how to rank projects: The PROMETHEE method. Eur. J. Oper. Res., 24 (2), 228-238 (11 pages).

Chien, M. K.; Shih, L. H., (2007). An empirical study of the implementation of green supply chain management practices in the electrical and electronic industry and their relation to organizational performances. Int. J. Environ. Sci. Tech., 4 (3), 383-394 (12 pages).

Dayer, J. S., (2005). MAUT-Multiattribute utility theory. Figueira, J.; Greco, S.; Ehrgott, M. (Eds.). Multiple criteria 
decision analysis: State of the art surveys. Springer Science and Business Media, Inc., Boston.

Deason, J., (1984). A multi-objective decision support system for water project portfolio selection. Ph.D. Dissertation, University of Virginia, USA.

De Keyser, W.; Peeters, P., (1994). ARGUS - A new multiple criteria method based on the general idea of outranking. Paruccini, M, (Ed.). Applying multiple criteria aid for decision to environmental management, Kluwer Academic Publishers, Dordrecht.

De Keyser, W.; Peeters, P., (1996). A note on the use of PROMETHEE multicriteria methods. Eur. J. Oper. Res., 89 (3), 457-461 (5 pages).

Diakoulaki, D.; Antunes, C. H.; Martins, A. G., (2005). MCDA and energy planning. Figueira, J., Greco, S., Ehrgott, M. (Eds.). Multiple criteria decision analysis: State of the art surveys. Springer Science and Business Media, Inc., Boston.

Ferreira, P. F. V., (2007). Electricity power planning in portugal: The role of wind energy. Ph.D. Dissertation, University of Minho, Portugal.

Figueira, J.; Mousseau, V.; Roy, B., (2005). ELECTRE methods. Figueira, J.; Greco, S.; Ehrgott, M., (Eds.). Multiple criteria decision analysis: State of the art surveys. Springer Science and Business Media, Inc., Boston.

Fishburn, P. C., (1974). Lexicographic orders, utilities and decision rules: A survey. Manage. Sci., 20 (11), 1442-1471 (30 pages).

Fishburn, P. C., (1975). Axioms for lexicographic preferences. Rev. Econom. Stud., 42 (3), 415-419 (5 pages).

Georgopoulou, E.; Lalas, D.; Papagiannakis, L., (1997). A multicriteria decision aid approach for energy planning problems: The case of renewable energy option. Eur. J. Oper. Res., 103 (1), 38-54 (17 pages).

Gershon, M., (1981). Model choice in multi-objective decision making in natural resource systems. Ph.D. Dissertation. University of Arizona. USA.

Grubb, M.; Edmonds, J.; ten Brink, P.; Morrison, M., (1993). The cost of limiting fossil-fuel $\mathrm{CO}_{2}$ emissions: A survey and analysis. in: Socolow, R. H.; Anderson, D.; Harte, J. (Eds.). Annual review of energy and the environment. Annual Reviews, California.

Guitouni, A.; Martel, J. M., (1998). Tentative guidelines to help choosing an appropriate MCDA method. Eur. J. Oper. Res., 109 (2), 501-521 (21 pages).

Haralambopoulos, D. A.; Polatidis, H., (2003). Renewable energy projects: Structuring a multicriteria group decisionmaking framework. Renew. Energy, 28 (6), 961-973 (13 pages).

Hiremath, R. B.; Shikha, S.; Ravindranath, N. H., (2007). Decentralized energy planning; modeling and applicationa review. Renew. Sustain. Energy Rev., 11 (5), 729-752 (24 pages).

Hobbs, B., (1995). Optimisation methods for electric utility resource planning. Eur. J. Oper. Res., 83 (1), 1-20 (21 pages).

Hourcade, J. C.; Richels, R.; Robinson, J., (1996). Estimating the cost of mitigating greenhouse gases. Bruce, J. P.; Lee, H.; Haites, E. F., (Eds.). Climate change: Economic and social dimensions of climate change, contribution of working group III to the second assessment report of the IPCC. University Press, Cambridge.
Huang, J.; Poh, K.; Ang, B., (1995). Decision analysis in energy and environmental modeling. Energy, 20 (9), 843-855 (23 pages).

Huang, P. S.; Shih, L. H., (2009). Effective environmental management through environmental knowledge management. Int. J. Environ. Sci. Tech., 6 (1), 35-50 (16 pages).

Jebaraj, S.; Iniyan, S., (2006). A review of energy models. Renew. Sustain. Energ. Rev., 10 (4), 281-311 (31 pages).

Kahraman, C.; Kaya, I.; Cebi, S., (2009). A comparative analysis for multiattribute selection among renewable energy alternatives using fuzzy axiomatic design and fuzzy analytic hierarchy process. Energy, 34 (10), 1603-1616 (14 pages).

Karapidakis, E. S.; Tsave, A. A.; Soupios, P. M.; Katsigiannis, Y. A., (2010). Energy efficiency and environmental impact of biogas utilization in landfills. Int. J. Environ. Sci. Tech., 7 (3), 599-608 (10 pages).

Kleinpeter, M., (1995). Energy planning and policy, John Wiley.

Linkov, I.; Varghese, A.; Jamil, S.; Seager, T. P.; Kiker, G.; Bridges, T., (2004). Multi-criteria decision analysis: A framework for structuring remedial decisions at the contaminated sites. Linkov, I.; Ramadan, A. B., (Eds.). Comparative risk assessment and environmental decision making. Springer, New York.

Løken, E., (2007). Use of multicriteria decision analysis methods for energy planning problems. Renew. Sustain. Energ. Rev., 11 (7), 1584-1595 (12 pages).

Macharis, C.; Brans, J.P.; Mareschal, B., (1998). The GDSS PROMETHEE procedure -a PROMETHEE-GAIA based procedure for group decision support. J. Decision Sys., 7 (1), 283-307 (25 pages).

Martel, J. M.; Matarazzo, B., (2005). Other outranking approaches. Figueira, J.; Greco, S.; Ehrgott, M., (Eds.). Multiple criteria decision analysis: State of the art surveys. Springer Science and Business Media, Inc., Boston.

Paelinck, J. H. P., (1976). Qualitative multiple criteria analysis, environmental protection and multiregional development. Pap. Reg. Sci., 36 (1), 59-74 (16 pages).

Paelinck, J. H. P., (1977). Qualitative multiple criteria analysis: An application to airport location. Environ. Plan., 9 (8), 883-895 (13 pages).

Pandey, R., (2002). Energy policy modelling: Agenda for developing countries. Energ. Policy, 30 (2), 97-106 (10 pages).

Pohekar, S.; Ramachandran, M., (2004). Application of multicriteria decision making to sustainable energy planning-A review. Renew. Sustain. Energ. Rev., 8 (4), 365-381 (17 pages).

Polatidis, H.; Haralambopoulos, D. A.; Munda, G.; Vreeker, R., (2006). Selecting an appropriate multi-criteria decision analysis technique for renewable energy planning. Energ. Source B., 1, 181-193 (13 pages).

Roy, B., (1975). Vers une méthodologie générale d'aide à la décision. Revue METRA. 14 (3), 459-97 (39 pages).

Roy, B., (1990). The outranking approach and the foundations of ELECTRE methods. Bana e Costa, C. A. (Ed.). Readings in multiple criteria decision aid. Springer-Verlag, Berlin.

Roy, B., (1991). The outranking approach and the foundations of ELECTRE methods. Theor. Decis., 31 (1), 49-73 (25 pages). 
Roy, B., (1996). Multicriteria methodology for decision aiding, volume 12 of nonconvex optimization and its applications. Kluwer Academic Publishers.

Roy, B., (2005). Paradigms and challenges. Figueira, J.; Greco, S.; Ehrgott, M., (Eds.), Multiple criteria decision analysis: State of the art surveys, Springer Science and Business Media, Inc., Boston.

Saaty, T. L., (2000). Fundamentals of the analytic hierarchy process. RWS Publications.

Saaty, T. L., (2005). The analytic hierarchy and analytic network processes for the measurement of intangible criteria and for decision-making. Figueira, J.; Greco, S.; Ehrgott, M. (Eds.). Multiple criteria decision analysis: State of the art surveys. Springer Science and Business Media, Inc., Boston. Schrattenholzer, L., (2005). Energy planning methodologies and tools. Encyclopedia of Life Support Systems. EOLSS Publishers, Oxford, UK.

Tecle, A., (1988). Choice of multicriteria decision making techniques for watershed management. Ph.D. Dissertation. University of Arizona, USA.

Tehrani, S. M.; Karbassi, A. R.; Ghoddosi, J.; Monavvari, S. M.; Mirbagheri, S. A., (2009). Prediction of energy consumption and urban air pollution reduction in e-shopping. J. Food, Agric. Environ., 7 (3 \& 4), 898-903 (5 pages).

Tehrani, S. M.; Karbassi, A. R.; Monavari, S. M.; Mirbagheri, S. A., (2010). Role of E-shopping management strategy in urban environment. Int. J. Environ. Res., 4 (4), 681-690 (10 pages).

Thery, R.; Zarate, P., (2009). Energy planning: a multi-level and multicriteria decision making structure proposal. Central Eur. J. Oper. Res., 17 (3), 265-74 (10 pages).
Tuzkaya, U. R. (2009). Evaluating the environmental effects of transportation modes using an integrated methodology and an application. Int. J. Environ. Sci. Tech., 6 (2), $277-$ 290 (14 pages).

Tuzkaya, G.; Ozgen, A.; Ozgen, D.; Tuzkaya, U. R., (2009). Environmental performance evaluation of suppliers: A hybrid fuzzy multicriteria decision approach. Int. J. Environ. Sci. Tech., 6 (3), 477-490 (14 pages).

UN, (2002). Guidelines on strategic planning and management of the energy sector. United Nations. Economic and Social Commission for Asia and the Pacific.

van Beeck, N. M. J. P., (1999). Classification of energy models. Econpapers. Available at: http://econpapers.repec.org/paper/ dgrkubrem/777.htm.

Voogd, H., (1982). Multicriteria evaluation with mixed qualitative and quantitative data. Environ. Plan., B (9), 221236 (16 pages).

Wang, J.; Jing, Y.; Zhang, C.; Zhao, J., (2009). Review on multi-criteria decision analysis aid in sustainable energy decision-making. Renew. Sustain. Energ. Rev., 13 (9), 22632278 (16 pages).

WCED, (1987). Our common future. World Commission on Environmental and Development. New York: Oxford University Press.

WEC, (1986). Energy terminology - A Multi-Lingual Glossary. World Energy Conference, $2^{\text {nd. }}$ Ed. Pergamon Press.

Zhou, P.; Ang, B. W.; Poh, K. L., (2006). Decision analysis in energy and environmental modeling: An update. Energy. 31 (14), 2604-2622 (19 pages).

\section{AUTHOR (S) BIOSKETCHES}

Bagheri Moghaddam, N., Ph.D. candidate, Department of Management and Accounting , Allameh Tabataba'I University, Tehran, Iran. Email: nbagheri1382@yahoo.com

Nasiri, M., M.Sc. student, Department of Industrial Engineering, AmirKabir University of Technology, Tehran, Iran. Email: m.nasiri@aut.ac.ir

Mousavi, S. M., M.Sc. student, Department of Economic and Management, Sharif University of Technology, Tehran, Iran. Email: majidi31@yahoo.com 